\title{
Pharmacokinetics of $\alpha$-Pyrrolidinovalerophenone in Male Rats with and without Vaccination with an $\alpha$-Pyrrolidinovalerophenone Vaccine
}

\author{
Samantha J. McClenahan ${ }^{1,2}$, Melinda G. Gunnell ${ }^{1}$, and Samuel M. Owens ${ }^{1}$ \\ ${ }^{1}$ Department of Pharmacology and Toxicology, College of Medicine, University of Arkansas for Medical Sciences, Little \\ Rock, AR, USA; ${ }^{2}$ Department of Anesthesiology, Vanderbilt University for Medical Sciences, Nashville, TN, USA
}

Corresponding author: S. Michael Owens, University of Arkansas for Medical Sciences, Department of Pharmacology and Toxicology, 4301 West Markham Street, \#611, Little, Rock, AR 72205, USA; TEL: (501)-227-0661; email: mowens@uams.edu

Received, March 21, 2021; Revised, April 27, 2021; Accepted, May 11, 2021; Published, May 31, 2021

\begin{abstract}
PURPOSE: $\alpha$-Pyrrolidinovalerophenone ( $\alpha$-PVP) is a second-generation synthetic cathinone which acts as an inhibitor at the dopamine and norepinephrine transporters in the brain. These novel studies determined the pharmacokinetics (PK) of $\alpha$-PVP in rats and then evaluated the effects of an $\alpha$-PVP vaccine on the PK profile. METHODS: Adult male Sprague-Dawley rats were randomly divided into treatment groups $(\mathrm{n}=$ 24/group) in which the vaccinated rats received an initial and two booster immunizations of the $\alpha$-PVP vaccine at 0,3 , and 9 wks. Control rats received saline injections. $\alpha$-PVP $(0.56,1,3 \mathrm{mg} / \mathrm{kg}, \mathrm{sc})$ was then administered to both groups between 11-12 weeks and serum samples were collected for determination of $\alpha$-PVP serum concentrations by LC-MS/MS ( $n=6$ rats/treatment/time). At 13 weeks, brain, heart and kidney concentrations of $\alpha$-PVP were determined by LC-MS/MS after administration of $1 \mathrm{mg} / \mathrm{kg} \alpha$-PVP ( $\mathrm{n}=4-5 \mathrm{rats} /$ treatment/time). RESULTS: PK values in control rats showed dose-dependent increases in maximum serum concentrations $\left(\mathrm{C}_{\max }\right)$ and area under the curve $\left(\mathrm{AUC}_{\mathrm{inf}}\right)$ values with an elimination half-life $\left(\mathrm{t}_{1 / 2}\right)$ of approximately $2.1 \mathrm{~h}$. $\alpha$-PVP exhibited linear PK profile in control rats. Vaccinated rats had significantly $(\mathrm{p}<0.05)$ higher serum $\mathrm{C}_{\max }$ and $\mathrm{AUC}_{\text {inf }}$ values than controls, and significantly reduced total body clearance, volume of distribution and $\mathrm{t}_{1 / 2}$ values. Vaccinated rats had significantly lower $\alpha$-PVP concentrations in the brain, heart, and kidney in comparison to control rats at early time points. CONCLUSION: Vaccination with the novel $\alpha$-PVP vaccine significantly altered serum PK leading to a time-dependent reduction in brain, kidney and heart concentrations of $\alpha$-PVP compared to controls.
\end{abstract}

\section{INTRODUCTION}

$\alpha$-Pyrrolidinovalerophenone $(\alpha-\mathrm{PVP})$ is a second-generation synthetic cathinone that is classified as a Schedule 1 compound in the United States. $\alpha$-PVP is one of the most potent synthetic cathinones that inhibits dopamine and norepinephrine reuptake in the brain with little effect on the serotonin transporter (1-4). In behavioral assays with rodents, $\alpha$-PVP causes increased hyperlocomotion, substitutes for other psychostimulants, and is self-administered (3,5-8). Metabolism of $\alpha$-PVP using in vitro human liver microsomes yields six potential phase 1 metabolites with $\alpha$-PVP lactam and $\beta$-hydroxy $\alpha$-PVP as the most commonly formed metabolites $(2,9,10)$.

With a paucity of medications for the treatment of substance use disorders (SUD), vaccines continue to be developed and tested as a potential treatment for cocaine, methamphetamine, nicotine and opioid SUD (11-15). Vaccines for drugs of abuse function by stimulating in vivo production of polyclonal antibodies against the drug of abuse which bind the drug with high affinity $(16,17)$ in serum and thereby limit its distribution into organs such as the brain $(18,19)$. Recently, there was a report of a vaccine for $\alpha$-PVP that was found to lower wheel running activity and alter iv self-administration of drug patterns in male rats, but this study by Nguyen et al. did not evaluate how the vaccine altered the PK properties of $\alpha$-PVP (20).

Understanding drug PK aids in the development of vaccine treatments since the antibodies act as PK antagonists, which reduce the volume of distribution, reduce total body clearance of the drug, and under optimal conditions reduce the amount and rate of entry of drugs of abuse into organs like the brain (15). We previously reported the development of a bi-specific vaccine for $\alpha$-PVP and its analog 3,4-methylenedioxypyrovaleone (MDPV) that produces high affinity antibodies for both drugs of abuse (21). Our prior study only evaluated PK 
changes of two doses $(0.56$ and $3 \mathrm{mg} / \mathrm{kg})$ at two time points ( 30 and $120 \mathrm{~min}$ ) in serum, brain, kidney and heart in control and vaccinated rats.

The purpose of the current studies was to determine the PK profile of $\alpha$-PVP after sc dosing and to expand on the more limited PK studies of $\alpha$ PVP after subcutaneous (sc) administration in rats (21). With these new data, we gained further insights into the pharmacokinetics of $\alpha$-PVP and how the bispecific vaccine-produced changes in $\alpha$-PVP halflife, volume of distribution and clearance.

ABBREVIATION. $\alpha$-PVP: $\alpha$-pyrrolidinovalerophenone; $\mathrm{AUC}_{\text {inf: }}$ area under the $\alpha$-PVP concentration time curve extrapolated to time infinity; $\mathrm{CL} / \mathrm{F}$ : estimated total body clearance; $\mathrm{C}_{\max }$ : maximum serum concentration; $\mathrm{IC}_{\mathrm{KLH}}$ : keyhole limpet hemocyanin; iv: intravenous, LCMS/MS: liquid chromatography-mass spectrometer/mass spectrometer; MDPV: 3,4-methylenedioxypyrovaleone; PBS: phosphate buffered saline; PK: pharmacokinetic; SD: Sprague Dawley; sc: subcutaneous; $\mathrm{t}_{1 / 2}$ : terminal elimination half-life; $\mathrm{Vd} / \mathrm{F}$ : estimated volume of distribution

\section{METHODS}

\section{Chemicals and reagents}

Racemic $\alpha$-pyrrolidinovalerophenone $\mathrm{HCl}$ was obtained from the National Institute on Drug Abuse drug supply program (Research Triangle Institute, Research Triangle Park, NC). All $\alpha$-PVP concentrations were calculated as the free base. For the vaccine, Sigma Adjuvant System (SAS) was purchased from Sigma-Aldrich (St. Louis, MO, USA). Keyhole limpet hemocyanin ( $\mathrm{IC}_{\mathrm{KLH}}$; Biosyn Corp, Carlsbad, CA), consisting of two stable subunit monomers with masses of $\sim 360$ and $\sim 390 \mathrm{kDa}$, was used as the antigenic carrier protein for conjugation to an $\alpha$-PVP hapten. This conjugate vaccine ( $\alpha$-PVP$\left.\mathrm{IC}_{\mathrm{KLH}}\right)$ led to the development of a bi-specific vaccine that cross reacted with $\alpha-P V P$ and MDPV (21). In this report the vaccine will be called an $\alpha$ PVP vaccine. All other chemicals were purchased from Thermo Fisher Scientific, Inc. (Waltham, MA) or Sigma-Aldrich Chemical Company (St. Louis, MO) unless otherwise noted.

\section{Animals and immunization}

Male Sprague-Dawley rats (8 weeks old) were purchased from Charles River (Kingston, NY). Rats were housed three per cage and food restricted to 20 $\mathrm{g}$ per day to maintain a stable body weight (300-350 g). Rats were divided randomly into two groups ( $n=24$ /group), phosphate buffered saline (PBS pH = 7.35) control or vaccine treatment. Rats assigned to the vaccine treatment $(\mathrm{n}=24)$ were injected in hind limbs (sc, $150 \mu \mathrm{l} / \mathrm{limb}, 300 \mu \mathrm{l}$ total) with the $\alpha$-PVP vaccine consisting of $100 \mu \mathrm{g}$ of $\alpha$-PVP-IC $\mathrm{KLH}_{\mathrm{KL}}$ in 150 $\mu 1$ of PBS mixed with $150 \mu$ l of Sigma Adjuvant System. Control rats were injected with $300 \mu$ of PBS. Rats received a booster vaccination or PBS injection at 3 and 9 weeks after initial vaccine or PBS injections. Optimal scheduling of immunization was based on previous experiments in our laboratory in mice with a methamphetamine-conjugate vaccine and in rats during the development of the bispecific vaccine $(21,22)$. All procedures were conducted in accordance with the Institutional Animal Care and Use Committee of the University of Arkansas for Medical Sciences and the Guide for Care and Use of Laboratory Animals (National Research Council, 2011).

\section{Pharmacokinetic studies}

Study design for the PK experiments was based on results from our previous publication of the design, synthesis and biological evaluation of this vaccine (21). In those studies, a functional titer of the rat's antiserum was measured using radioligand binding at weeks 5, 9, 11, and 16 for $\alpha$-PVP and MDPV. The results showed that the drug binding for both drugs was highest and essentially the same at weeks 11 and 16 with a very low variance. Thus, we reasoned the PK experiments for $\alpha$-PVP should be conducted during this time period.

At 11 weeks after initial immunization, control and $\alpha$-PVP vaccine treated rats were randomly assigned within treatments into three dosing groups ( $n=8 /$ group/treatment) for use in $\alpha$-PVP PK experiments followed by tissue distribution studies using the same rats. Randomization was determined using a random number generator to assign three rats within a cage to one of the three $\alpha$-PVP doses $(0.56$, $1,3 \mathrm{mg} / \mathrm{kg}$, sc) for blood collections. Group assignments were only used to determine during which $\alpha$-PVP dose each rat would have blood samples collected. All rats were administered ascending doses of $\alpha$-PVP $(0.56,1,3 \mathrm{mg} / \mathrm{kg}, \mathrm{sc})$ with each dose separated by 48-72 h.

For collecting blood via tail vein by venous puncture, tails were thoroughly cleaned and sampled starting at the tip of the tail and moving towards the base for additional sampling to preserve the vein and avoid contamination. The blood samples $(50-150 \mu \mathrm{l})$ were collected at $7-8$ time points while rats were restrained. These time points were $5 \mathrm{~m}, 30 \mathrm{~m}, 2,3,4$, 6 , and $8 \mathrm{~h}$ for the $0.56 \mathrm{mg} / \mathrm{kg}$ group with an additional $10 \mathrm{~h}$ sample for the 1 and $3 \mathrm{mg} / \mathrm{kg} \alpha$-PVP group and an additional $12 \mathrm{~h}$ sample for the $3 \mathrm{mg} / \mathrm{kg} \alpha-P V P$ group. The total blood volume collected during each 
experiment was $<1 \%$ of rat's total body weight. Blood samples were maintained at $4^{\circ} \mathrm{C}$ to allow for clotting, centrifuged $7 \mathrm{~min}$ at $21,000 \mathrm{rcf}$ at $4{ }^{\circ} \mathrm{C}$ for serum collection and stored at $-80^{\circ} \mathrm{C}$. A blood sample at $48-72 \mathrm{~h}$ after each dose was collected to ensure no $\alpha$-PVP was detectable in the serum.

Two weeks after the administration of the final $\alpha$-PVP dose $(3 \mathrm{mg} / \mathrm{kg}$ ) from the initial serum PK studies, rats were administered $1 \mathrm{mg} / \mathrm{kg}$ of $\alpha$-PVP (sc) for tissue distribution studies. The rats were sacrificed at $30 \mathrm{~m}, 2,4,6$, and $8 \mathrm{~h}$ after drug administration ( $\mathrm{n}=4-5$ rats/treatment). Blood, brain, heart, and kidney were collected from each rat. Organs were quickly weighed, placed in liquid nitrogen, and then stored at $-80^{\circ} \mathrm{C}$. Blood samples were kept on ice, allowed to clot for $>1 \mathrm{~h}$, and centrifuged at 21,000 rcf. Serum was collected and stored at $-80^{\circ} \mathrm{C}$.

\section{LC-MS/MS (liquid chromatography-mass spectrometer/mass spectrometer) analysis of $\alpha$ - PVP concentrations}

Racemic $\alpha$-PVP serum and tissue concentrations were determined at the McWhorter School of Pharmacy, Pharmaceutical Sciences Research Institute at Samford University, (Birmingham, AL). The chromatography system consisted of a HPLC (high performance liquid chromatography; Shimadzu, Columbia, MD) equipped with dual HPLC pumps, an autosampler and an in-line degasser. Detection was performed using an Applied BioSystems 4000 QTRAP (Applied BioSystems, Forest City, CA) LC-MS/MS. Mass calibration, data acquisition and quantitation were performed using Applied BioSystems software (V1.6.2). A Phenomenex Luna Omega Polar C18 100 x $2.1 \mathrm{~mm}$ $5 \mu \mathrm{m}$ analytical column (Torrance, CA) was used with a gradient of distilled water with $0.1 \%$ formic acid and acetonitrile with $0.1 \%$ formic acid at a flow rate of $0.4 \mathrm{~mL} / \mathrm{min}$.

Rat serum $(20 \mu \mathrm{l})$ proteins were precipitated with ice cold acetonitrile ( $n=6 /$ group/treatment). Based on a power analysis, only 6 of the 8 rats/group/treatment were analyzed for the initial PK study with the additional 2 rats serving as supporting subjects, if needed, and to complete the numbers for the tissue distribution study. After centrifugation for $5 \mathrm{~min}$ at $21,000 \mathrm{x} \mathrm{g}$, the supernatant was analyzed by LC-MS/MS in the positive ion mode with $10 \mathrm{ng} / \mathrm{mL}$ of $\alpha$-pyrrolidinopentiophenone- $d_{8}$ hydrochloride $(\alpha$ PVP- $d_{8}$; Cayman Chemical, Ann Arbor, MI) as the internal standard. Based on the results from method validation the lower limit of quantitation (LLOQ) across the validated range was $0.5 \mathrm{ng} / \mathrm{mL}$ and the upper limit of quantitation (ULOQ) was $1000 \mathrm{ng} / \mathrm{mL}$. The accuracy and precision of the method showed average values in the range of $85 \%$ to $115 \%$ and coefficients of variation of less than $15 \%$ for the quality control concentrations, respectively. Over a concentration range of $1-500 \mathrm{ng} / \mathrm{mL}$, recovery of $\alpha$ PVP averaged $91.7 \%$ and $101 \%$, respectively. $\alpha$-PVP response in the standards averaged $99.2 \%$ in extracted serum samples for at least $59 \mathrm{~h}$ at $4{ }^{\circ} \mathrm{C} . \alpha$ PVP was stable through three freeze thaw cycles. Methods were also developed and validated for determining concentrations of $\alpha$-PVP in brain, heart and kidney. The calibration range for all tissue samples was 5, 50, and $500 \mathrm{ng} / \mathrm{ml}$. Rat brains were homogenized with 4 volumes (1:5) of cold $5 \mathrm{mM}$ ammonium acetate buffer ( $n=4-5$ rats/treatment). Heart and kidney from the same rats were homogenized with 9 volumes (1:10) of ammonium acetate buffer. The drug was extracted, and drug concentrations were determined by LC-MS/MS as described for serum (see above).

\section{PK data and statistical analysis}

The PK parameters were determined using Phoenix WinNonLin (V8, Certara USA, Princeton, NJ). Noncompartmental analysis with extravascular administration by the sc route was chosen as the PK model. The best-fit line to each rats $\alpha$-PVP log-linear concentration-time terminal elimination phase at each dose was selected based on WinNonLin best-fit line values and visual inspection. PK values for the terminal elimination half-life $\left(\mathrm{t}_{1 / 2}\right)$, area under the $\alpha$ PVP concentration time curve extrapolated to time infinity $\left(\mathrm{AUC}_{\mathrm{inf}}\right)$ and observed maximum concentration $\left(\mathrm{C}_{\max }\right)$ were determined. The estimated total body clearance $(\mathrm{CL} / \mathrm{F})$ and estimated volume of distribution $(\mathrm{Vd} / \mathrm{F})$ were also calculated for $\alpha$-PVP in each rat. The $\mathrm{CL} / \mathrm{F}$ and $\mathrm{Vd} / \mathrm{F}$ values were considered estimates, since $\mathrm{AUC}_{\mathrm{inf}}$ was not determined after an iv dose in the current study to calculate actual bioavailability. These values for $\mathrm{CL} / \mathrm{F}$ and $\mathrm{Vd} / \mathrm{F}$ were used with the assumption that the dose was completely absorbed after sc dosing and that the fraction of the dose absorbed was $1.0(100 \%$ bioavailable).

Statistical comparisons of PK values were computed using GraphPad Prism (V7, San Diego, CA). Results are presented as mean \pm SD except for $\mathrm{t}_{1 / 2}$ which are reported as harmonic mean \pm a pseudo standard deviation as described by Lam et al. (23). 
PK parameters were compared using a two-way ANOVA. Statistical significance was declared at $\mathrm{p}<0.05$.

\section{RESULTS}

\section{Pharmacokinetic data for $\alpha$-PVP in control and vaccinated animals}

Figure 1 shows the average rat serum concentration versus time plots of $\alpha$-PVP after sc administration of three different doses of $\alpha$-PVP in non-vaccinated controls and vaccinated male SD rats $(n=6 /$ treatment). This analysis was for graphical presentation in this figure only. The actual PK parameters in Tables 1 and 2 were based on the average values calculated from each rat's data set for each dose.

Table 1 summarizes the PK parameters of $\alpha$ PVP calculated from the concentrations versus time data sets of individual rats. Table 2 shows the PK values for $\mathrm{C}_{\max }$ and $\mathrm{AUC}_{\mathrm{inf}}$ corrected for $\alpha$-PVP dose. Vaccination with the $\alpha$-PVP vaccine significantly altered pharmacokinetic parameters of $\alpha$-PVP (Table 1 and Figure 2). There was a main effect of treatment on the $\mathrm{CL} / \mathrm{F}, \mathrm{Vd} / \mathrm{F}$, observed $\mathrm{C}_{\max }$, and $\mathrm{AUC}_{\text {inf }}$ values for $\alpha-P V P$. $C L / F$ and $V d / F$ values were significantly $(p<0.05)$ decreased in comparison to control rats, while $\mathrm{C}_{\max }$ and $\mathrm{AUC}_{\mathrm{inf}}$ were significantly increased in vaccinated rats. There was a significant decrease in half-life in vaccinated rats at 0.56 and $1.0 \mathrm{mg} / \mathrm{kg}$ sc administration of $\alpha$-PVP.

\section{Organ concentration-time profiles of $\alpha-P V P$ in control and vaccinated rats}

Following completion of individual rat serum PK studies (Figure 1 and Tables 1, 2, and 3), the same animals were used for studies of determination of organ concentrations of $\alpha-\mathrm{PVP}$ at $1 \mathrm{mg} / \mathrm{kg}$ sc over time in control and vaccinated rats $(n=4-5$ rats/treatment/time point). There was a statistically significant $(p<0.05)$ main effect of treatment for brain, kidney, and heart with vaccinated rats having lower concentrations of $\alpha$-PVP than non-vaccinated rats (Figure 3 B-D). Population serum concentrations were significantly higher in vaccinated compared to non-vaccinated rats (Figure $3 \mathrm{~A}$ ). Figure 4 compares the relative changes in PK parameters of $\alpha$-PVP represented as a ratio of tissue to serum concentrations. The concentrations were derived from the data points used to plot Figure 3.
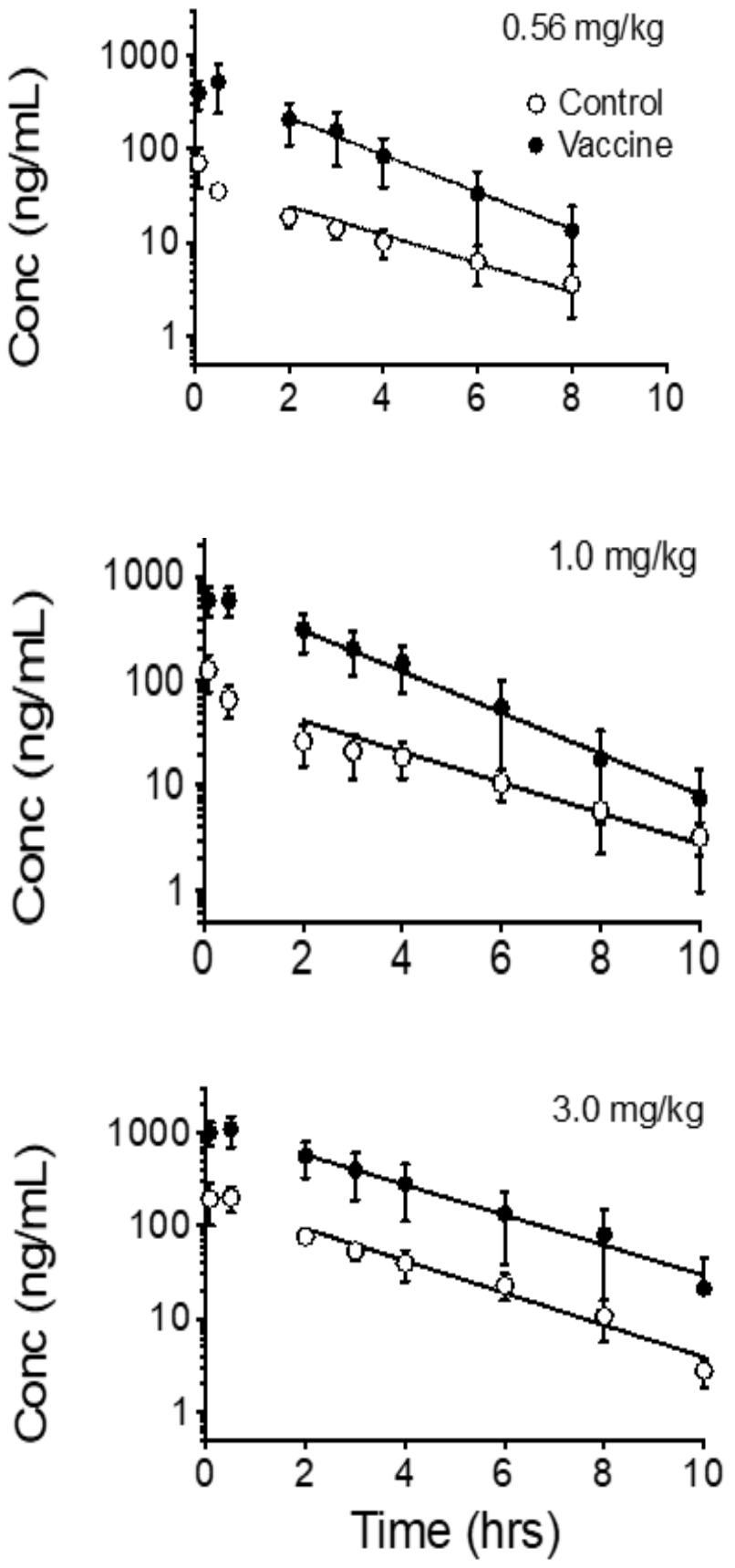

Figure 1. Average serum concentration versus time curves of $\alpha$-PVP after a sc dose of $0.56,1.0$ and $3.0 \mathrm{mg} / \mathrm{kg} \alpha-P V P$ in non-vaccinated control and vaccinated male SD rats ( $n=6$ per group). Symbols denote average observed concentration. The best-fit line for the terminal elimination phase on this plot is based on the average individual concentrations represented as mean \pm SD. See Table 1 for statistical comparison of all pharmacokinetic values after sc dosing based on the noncompartmental PK analysis of individual rat data sets at each dose and each treatment. 

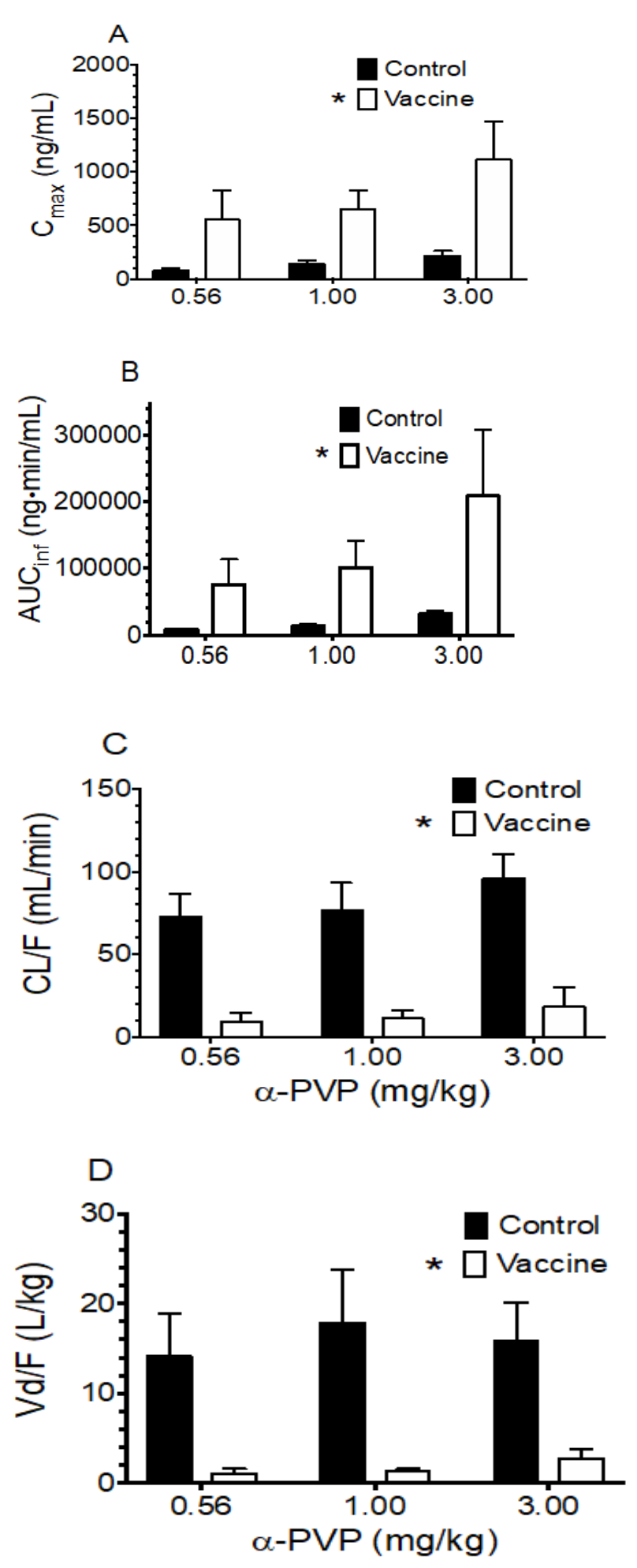

Figure 2. Comparison of pharmacokinetic parameters in control and vaccinated rats at three different $\alpha$-PVP doses. These plots were created from the data in Table 1 and 2. Asterisks indicate significant difference in main effect from non-vaccinated control rats $(\mathrm{p}<0.05)$.
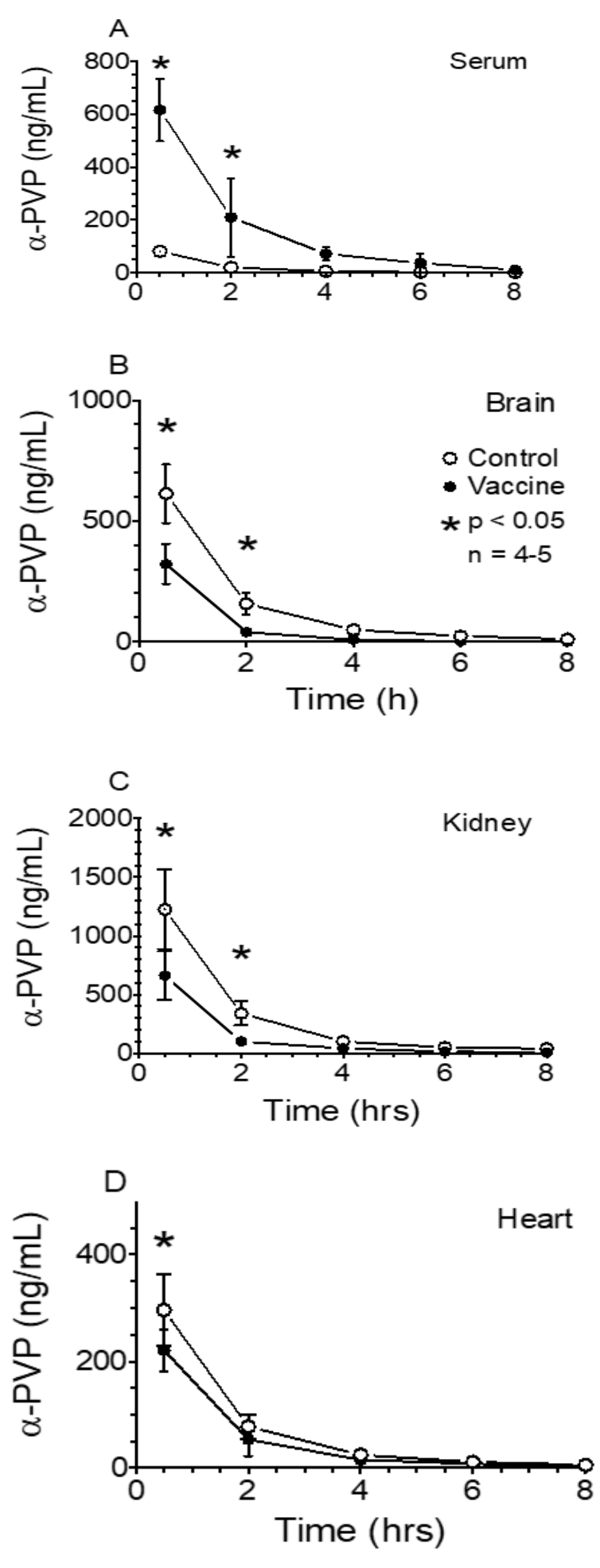

Figure 3. Concentrations of $\alpha-P V P$ in serum, brain, kidney, and heart after $1 \mathrm{mg} / \mathrm{kg} \alpha-\mathrm{PVP}$ (sc) in control and vaccinated male $S D$ rats $(n=4-5$ rats/treatment/time; mean $\pm \mathrm{SD}$ ). Please note that the $y$-axis on each plot is a different concentration range. Asterisks indicate significant difference from non-vaccinated control rats $(\mathrm{p}<0.05)$. 

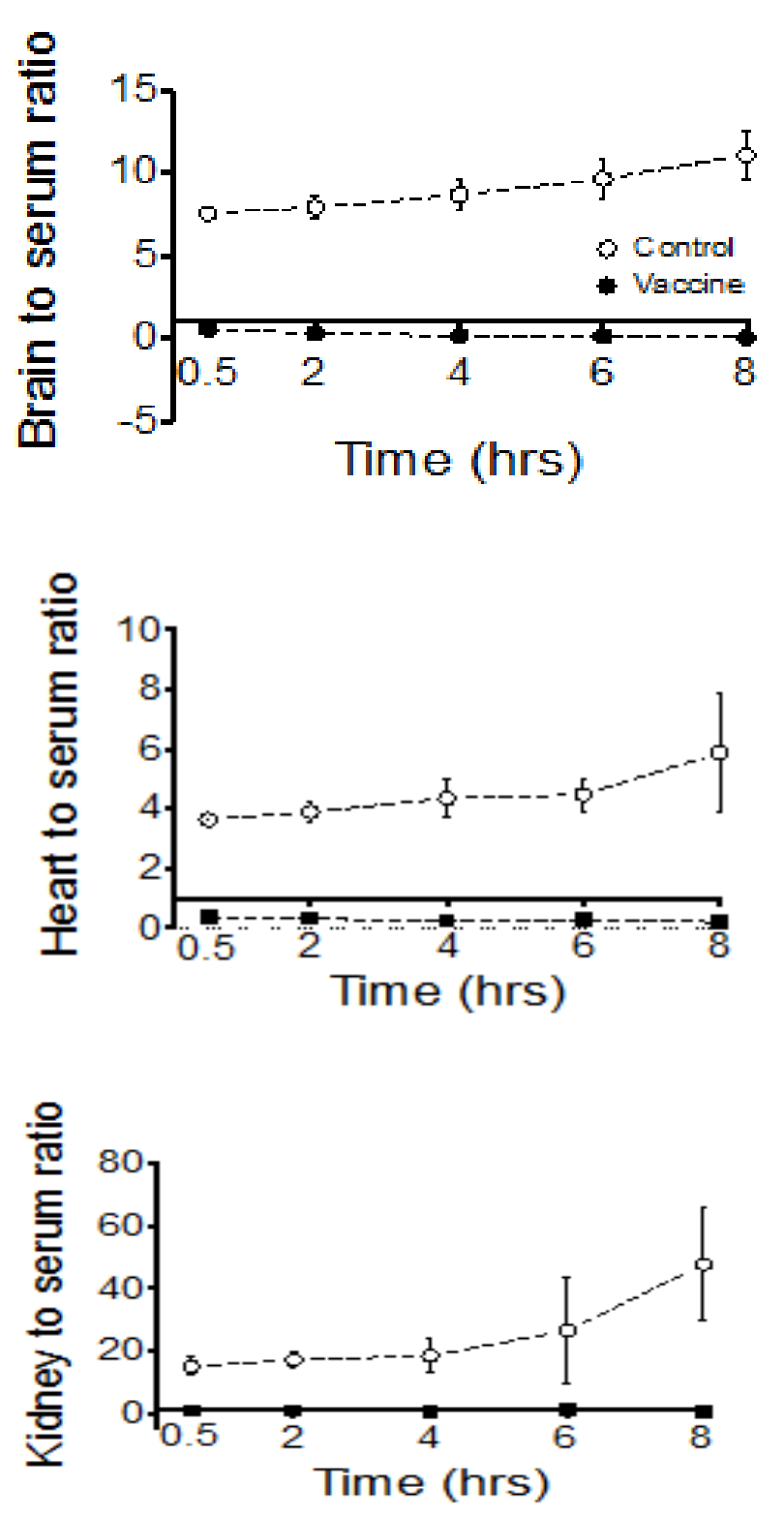

Figure 4. Serum to tissue ratios over time in the brain, heart and kidney after $1 \mathrm{mg} / \mathrm{kg} \alpha$-PVP (sc) in control and vaccinated male $\mathrm{SD}$ rats $(\mathrm{n}=4-5$ rats/treatment/time; mean \pm SD). Please note that the $y$-axis on each plot is a different ratio range.

\section{DISCUSSION}

This study reports the pharmacokinetics of $\alpha$-PVP across multiple doses in serum and tissue organs in rats, and the PK profile with and without vaccination with an $\alpha$-PVP vaccine. Human users report orally administering $1-2 \mathrm{mg}$ of $\alpha-\mathrm{PVP}$ to induce psychoactive effects and 20-25 $\mathrm{mg}$ of $\alpha$-PVP to achieve "strong" effects (24). This corresponds to a range of $0.014-0.36 \mathrm{mg} / \mathrm{kg}$ of $\alpha$-PVP dose in a 70 $\mathrm{kg}$ individual. Human blood samples of intoxicated
$\alpha$-PVP users that sought medical attention or had impaired driving range from $5-90 \mathrm{ng} / \mathrm{mL}(25,26)$. Fatalities involving $\alpha$-PVP use have blood concentrations ranging from 33 to $>20,000 \mathrm{ng} / \mathrm{mL}$, with the large toxicity range attributable to the unknown time of dose administration (26-29). In the current study, the serum concentrations of $\alpha$-PVP in control male SD rats after administration of $3 \mathrm{mg} / \mathrm{kg}$ reached an average observed $\mathrm{C}_{\max }$ value of 291 $\mathrm{ng} / \mathrm{mL}$ (Table 1), which is high compared to selfreported values in humans, but much lower than values associated with a human fatality.

While the average terminal elimination halflife of $\alpha$-PVP in control rats ranged from 1.82 to 2.54 $\mathrm{h}$ (average of range values $=2.18 \mathrm{~h}$, Table 1$)$, there was only a significant dose-dependent difference between $t_{1 / 2}$ values in control rats after $\mathrm{sc}$ administration of 0.56 and $1 \mathrm{mg} / \mathrm{kg} \alpha-P V P$. In comparison to the $\alpha$-PVP structural analog MDPV, the average $t_{1 / 2}$ of $\alpha$-PVP $(2.1 \mathrm{~h})$ is longer than the average $t_{1 / 2}$ of racemic MDPV at $1.3 \mathrm{~h}$ after $\mathrm{sc}$ administration in SD male rats (30). This means the $t_{1 / 2}$ of $\alpha$-PVP is $62 \%$ longer than the $t_{1 / 2}$ for MDPV after sc administration. If a difference of this magnitude was found between the $t_{1 / 2}$ values for the two drugs in humans it could attribute to the lower doses of $\alpha$-PVP self-administered in humans as compared with MDPV, despite similar affinities at norepinephrine and dopamine transporters and equipotency in in vivo assays (24).

Like MDPV, the data points from the $\alpha$-PVP terminal elimination phase are linear on a log concentration-time curve (Figure 1). This finding suggests linear PK properties over the range of $\alpha$ PVP doses studied. Also, $\alpha$-PVP does not show dosedependent differences in serum $\mathrm{AUC}_{\mathrm{inf}}$ (when corrected for each $\alpha$-PVP dose), CL/F, or $V d / F$ values (Tables 1 and 2) in controls. A limitation to this second conclusion is the assumption that the bioavailability after sc dosing is approximately $100 \%$. Nevertheless, these data suggest $\alpha$-PVP has linear pharmacokinetics, which was also reported for sc administered MDPV by Horsley et al. (31) in male SD rats.

Active vaccination of the rats with the $\alpha$-PVP vaccine significantly altered the serum pharmacokinetics of $\alpha$-PVP (Figure 2). The apparent $\mathrm{CL} / \mathrm{F}$ and $\mathrm{Vd} / \mathrm{F}$ of $\alpha-\mathrm{PVP}$ in vaccinated rats were significantly lower than controls, while the $\mathrm{C}_{\max }$ and $\mathrm{AUC}_{\mathrm{inf}}$ were significantly higher (Table 1, Figure 2). The $\mathrm{t}_{1 / 2}$ of $\alpha$-PVP was significantly lower after 0.56 and $1 \mathrm{mg} / \mathrm{kg} \alpha$-PVP; however, there was no 
Table 1. Pharmacokinetic parameters for $\alpha$-PVP after $0.56,1$, and $3 \mathrm{mg} / \mathrm{kg}$ sc administration of $\alpha$-PVP in control and vaccinated rats reported as mean $\pm \mathrm{SD}$. Asterisks indicate significant difference from the control rats at the same $\alpha$-PVP dose $(* \mathrm{p}<0.05)$.

\begin{tabular}{lllllll}
\hline $\begin{array}{l}\text { Dose } \\
(\mathbf{m g} / \mathbf{k g})\end{array}$ & $\begin{array}{l}\text { Treatment } \\
(\mathbf{N})\end{array}$ & $\begin{array}{l}\text { Half-life } \\
(\mathbf{h})\end{array}$ & $\begin{array}{l}\mathbf{C}_{\mathbf{m a x}} \\
(\mathbf{n g} / \mathbf{m L})\end{array}$ & $\begin{array}{l}\mathbf{A U C} \text { (inf } \\
(\mathbf{n g} \cdot \mathbf{m i n} / \mathbf{m L})\end{array}$ & $\begin{array}{l}\mathbf{C L} / \mathbf{F} \\
(\mathbf{m L} / \mathbf{m i n} / \mathbf{k g})\end{array}$ & $\begin{array}{l}\mathbf{V d} / \mathbf{F} \\
(\mathbf{L} / \mathbf{k g})\end{array}$ \\
\hline $\mathbf{0 . 5 6}$ & Control & 1.97 & 75 & 7943 & 73 & 14.1 \\
& $(6)$ & \pm 0.97 & \pm 24 & \pm 1791 & \pm 14 & \pm 4.7 \\
& Vaccine & 1.35 & 557 & 75932 & 9 & 1.1 \\
& $(6)$ & $\pm 0.23^{*}$ & $\pm 273^{*}$ & $\pm 37671^{*}$ & $\pm 5^{*}$ & $\pm 5.1^{*}$ \\
\hline $\mathbf{1 . 0}$ & Control & 2.54 & 135 & 13634 & 77 & 17.9 \\
& $(6)$ & \pm 0.58 & \pm 37 & \pm 3327 & \pm 17 & \pm 5.9 \\
& Vaccine & 1.33 & 646 & 100958 & 11 & 1.3 \\
& $(6)$ & $\pm 0.26^{*}$ & $\pm 181^{*}$ & $\pm 40732^{*}$ & $\pm 5^{*}$ & $\pm 0.3^{*}$ \\
\hline $\mathbf{3 . 0}$ & Control & 1.82 & 291 & 32712 & 94 & 15.6 \\
& $(6)$ & \pm 0.36 & \pm 71 & \pm 4501 & \pm 15 & \pm 4.0 \\
& Vaccine & 1.77 & 1117 & 208402 & 18 & 2.7 \\
& $(6)$ & \pm 0.55 & $\pm 354^{*}$ & $\pm 98795^{*}$ & $\pm 12^{*}$ & $\pm 1.0^{*}$ \\
\hline
\end{tabular}

Table 2. Pharmacokinetic parameters of $\alpha$-PVP corrected for dose after $0.56,1$, and $3 \mathrm{mg} / \mathrm{kg}$ (sc) administration of $\alpha$-PVP in control and vaccinated rats. The time to maximum concentration at all three doses occurred at either the 5 or 30 min blood collection time point in both the control and vaccinated rats (see Figure 1).

\begin{tabular}{llll}
\hline $\begin{array}{l}\text { Dose } \\
(\mathbf{m g} / \mathbf{k g})\end{array}$ & $\begin{array}{l}\text { Treatment } \\
(\mathrm{N})\end{array}$ & $\begin{array}{l}\mathbf{C}_{\mathbf{m a x}} \\
(\mathbf{n g} / \mathbf{m L})\end{array}$ & $\begin{array}{l}\mathbf{A U C} \text { inf } \\
(\mathbf{n g} \cdot \mathbf{m i n} / \mathbf{m L})\end{array}$ \\
\hline $\mathbf{0 . 5 6}$ & Control (6) & $134 \pm 42$ & $14184 \pm 3198$ \\
& Vaccine (6) & $994 \pm 487$ & $135592 \pm 67270$ \\
\hline $\mathbf{1 . 0}$ & Control (6) & $135 \pm 37$ & $13634 \pm 3327$ \\
& Vaccine (6) & $646 \pm 181$ & $100958 \pm 40732$ \\
\hline $\mathbf{3 . 0}$ & Control (6) & $77 \pm 24$ & $10904 \pm 1500$ \\
& Vaccine (6) & $372 \pm 118$ & $69467 \pm 32932$ \\
\hline
\end{tabular}

difference in $t_{1 / 2}$ between control and vaccinated rats at $3 \mathrm{mg} / \mathrm{kg} \alpha$-PVP (Table 1). In our study, the value for $\mathrm{Vd} / \mathrm{F}$ decreased more than the value for $\mathrm{CL} / \mathrm{F}$ in vaccinated rats. This resulted in a shorter $t_{1 / 2}$ compared to control rats, as predicted from the PK equation $\mathrm{t}_{1 / 2}=0.693 \times(\mathrm{Vd} / \mathrm{CL})$. This finding is also reported in studies of phencyclidine PK changes after treating rats or dogs with an anti-phencyclidine monoclonal antibodies or polyclonal antibody, respectively. In both of these phencyclidine studies, the $t_{1 / 2}$ of phencyclidine remained unchanged after antibody administration due to an equal order of magnitude decrease in $\mathrm{Vd} / \mathrm{F}$ and $\mathrm{CL} / \mathrm{F}(32,33)$. A similar equal order of magnitude change in $\mathrm{CL} / \mathrm{F}$ and $\mathrm{Vd} / \mathrm{F}$ was produced with the $\alpha-\mathrm{PVP}$ vaccine, which led to minimal change in $t_{1 / 2}$. Regardless, due to the reversible binding of $\alpha$-PVP with the antibody, $\alpha$ PVP having a $t_{1 / 2}$ vastly shorter than that of the antibodies in vaccinated animals (i.e., hrs vs weeks, respectively). Due to this reversible binding, the unbound antibodies are regenerated to inhibit multiple self-administrations of drug (34).

Changes in the pharmacokinetic properties of $\alpha$-PVP with this $\alpha$-PVP vaccine successfully decreased the distribution of $\alpha$-PVP into organs after sc administration of $1 \mathrm{mg} / \mathrm{kg} \alpha-P V P$ (Figure 3 ). In the brain and kidney, the vaccine significantly decreased the concentration of $\alpha$-PVP at 0.5 and $2 \mathrm{~h}$. The heart concentrations were only decreased at $0.5 \mathrm{~h}$. In a previous study from our group the duration of locomotor activity following a $1 \mathrm{mg} / \mathrm{kg} \alpha$-PVP dose averaged $191 \mathrm{~min}$ in the controls and $93 \mathrm{~min}$ in vaccinated rats (21). The total distance traveled was also significantly reduced in the vaccinated rats at this dose. While the rate of entry of $\alpha$-PVP into the brain is unknown, MDPV is reported to reach maximum brain concentrations in $\sim 0.5 \mathrm{~h}$ in male rats after sc administration (35). It is likely that the $\alpha$-PVP 
equilibrates in the brain similarly to MDPV and that the $\alpha$-PVP vaccine was able to blunt $\alpha$-PVP entry for at least the first $2 \mathrm{~h}$. This is important since the effects of the vaccine at a test dose of $3 \mathrm{mg} / \mathrm{kg} \alpha$-PVP sc failed to show significant reduction in brain concentration and failed to show effects on the total distance traveled (21).

An important observation was the very high values for the apparent $\mathrm{Vd} / \mathrm{F}$, which suggested extensive extravascular distribution. Average values for $\mathrm{Vd} / \mathrm{F}$ ranged from about 14.1 to $17.9 \mathrm{~L} / \mathrm{kg}$ (Table 1) after sc doses of 0.56 to $3.0 \mathrm{mg} / \mathrm{kg}$, which aligns with the range of $\mathrm{Vd} / \mathrm{F}$ values for MDPV (11.2 to 6.9 $\mathrm{L} / \mathrm{kg}$ ) after iv doses of 3 and $5.6 \mathrm{mg} / \mathrm{kg}$ (36). These very high values for the apparent volume of distribution suggest that the antibodies are under constant pressure to confine the $\alpha$-PVP in the serum and extracellular fluid compartments of the body, where the antibodies are circulating. Indeed, this is supported by the serum to tissue ratios in Figure 4 which shows elevated ratios for control rats across time compared to vaccinated rats with ratios below 1. These data provide important insights into the time-dependence of antibody sequestering of $\alpha$-PVP within the space that the antibody occupies. These observations in changing the volume of distribution of drug binding are not apparent in the plots of concentration over time (Figure 3 ).

\section{CONCLUSION}

In conclusion, male rats exhibited linear serum pharmacokinetics following sc doses of $\alpha$-PVP. Active vaccination with the $\alpha$-PVP vaccine significantly increased the concentration of $\alpha$-PVP in the serum leading to substantial decreased values for $C L / F$ and $V d / F$ of $\alpha$-PVP. Significant differences in the pharmacokinetics of $\alpha$-PVP between control and vaccinated rats begin to diminish at $3 \mathrm{mg} / \mathrm{kg}$ indicating the capacity of the anti- $\alpha$-PVP antibodies is likely being approached. Nonetheless, the $\alpha$-PVP vaccine treatment group showed significantly reduced $\alpha$-PVP concentrations in brain, heart, and kidney tissues after $1 \mathrm{mg} / \mathrm{kg}$ of $\alpha$-PVP. Considering that data from human use produces $\alpha$-PVP concentrations similar to those reported in this study, it is possible that this experimental therapy could have a similar positive effect in humans (23-27).

CONFLICT OF INTEREST. No conflict of interest to report.
ACKNOWLEDGEMENTS. This research was supported by grants from the National Institute on Drug Abuse (R01 DA039195 to SMO and F31 DA046121 to SJM) and from the National Institute of Health (T32 GM106999). We thank Dr. Greg Gorman of the McWhorter School of Pharmacy at Samford University in Birmingham, AL for the determination of $\alpha$-PVP concentrations in serum and tissue samples.

\section{REFERENCES}

1. Rickli A, Hoener MC, Liechti ME. Monoamine transporter and receptor interaction profiles of novel psychoactive substances: Para-halogenated amphetamines and pyrovalerone cathinones. Eur Neuropsychopharmacol. Elsevier; 2015 Mar 1;25(3):365-76. doi:10.1016/j.euroneuro.2014.12.012

2. Zawilska JB, Wojcieszak J. $\alpha$ Pyrrolidinophenones: a new wave of designer cathinones. Forensic Toxicol. Springer Japan; 2017 Jan 25;35(2):201-16. doi:10.1007/s11419-016-0353-6

3. Marusich JA, Antonazzo KR, Wiley JL, Blough BE, Partilla JS, Baumann MH. Pharmacology of novel synthetic stimulants structurally related to the "bath salts" constituent 3,4-methylenedioxypyrovalerone (MDPV). Neuropharmacology. 2014 Dec;87:206-13. doi:10.1016/j.neuropharm.2014.02.016

4. Eshleman AJ, Wolfrum KM, Reed JF, Kim SO, Swanson T, Johnson RA, et al. StructureActivity Relationships of Substituted Cathinones, with Transporter Binding, Uptake, and Release. J Pharmacol Exp Ther. American Society for Pharmacology and Experimental Therapeutics; 2017 Jan 1;360(1):33-47. doi:10.1124/jpet.116.236349

5. Aarde SM, Creehan KM, Vandewater SA, Dickerson TJ, Taffe MA. In vivo potency and efficacy of the novel cathinone $\alpha$ pyrrolidinopentiophenone and 3,4methylenedioxypyrovalerone: selfadministration and locomotor stimulation in male rats. Psychopharmacology (Berl). Springer Berlin Heidelberg; 2015;232(16):3045-55. doi:10.1007/s00213015-3944-8

6. Gatch MB, Dolan SB, Forster MJ. Comparative Behavioral Pharmacology of 
Three Pyrrolidine-Containing Synthetic Cathinone Derivatives. J Pharmacol Exp Ther. American Society for Pharmacology and Experimental Therapeutics; 2015 Aug 1;354(2):103-10.

doi:10.1124/jpet.115.223586

7. Gannon BM, Baumann $\mathrm{MH}$, Walther D, Jimenez-Morigosa C, Sulima A, Rice KC, et al. The abuse-related effects of pyrrolidinecontaining cathinones are related to their potency and selectivity to inhibit the dopamine transporter. Neuropsychopharmacol. 8 ed. Nature Publishing Group; 2018 Nov;43(12):2399-407. doi:10.1038/s41386018-0209-3

8. Gannon BM, Rice KC, Collins GT. Reinforcing effects of abused "bath salts" constituents 3,4-methylenedioxypyrovalerone and $\alpha$-pyrrolidinopentiophenone and their enantiomers. Behav Pharmacol. Behavioural Pharmacology; 2017 Oct;28(7):578-81. doi:10.1097/FBP.0000000000000315

9. Negreira N, Erratico C, Kosjek T, van Nuijs ALN, Heath E, Neels H, et al. In vitro Phase I and Phase II metabolism of $\alpha$ pyrrolidinovalerophenone $\quad(\alpha$-PVP), methylenedioxypyrovalerone (MDPV) and methedrone by human liver microsomes and human liver cytosol. Anal Bioanal Chem. Springer Berlin Heidelberg; 2015 May 27;407(19):5803-16. doi:10.1007/s00216015-8763-6

10. Meyer MR, Du P, Schuster F, Maurer HH. Studies on the metabolism of the $\alpha$ pyrrolidinophenone designer drug methylenedioxy-pyrovalerone (MDPV) in rat and human urine and human liver microsomes using GC-MS and LC-high-resolution MS and its detectability in urine by GC-MS. J Mass Spectrom. John Wiley \& Sons, Ltd; 2010 Dec 1;45(12):1426-42. doi:10.1002/jms.1859

11. Bremer PT, Kimishima A, Schlosburg JE, Zhou B, Collins KC, Janda KD. Combatting Synthetic Designer Opioids: A Conjugate Vaccine Ablates Lethal Doses of Fentanyl Class Drugs. Angewandte Chemie. 2016 Mar 7;128(11):3836-9. doi:10.1002/ange.201511654

12. Bremer PT, Schlosburg JE, Banks ML, Steele FF, Zhou B, Poklis JL, et al. Development of a Clinically Viable Heroin Vaccine. J Am Chem Soc. American Chemical Society; 2017
Jun 28;139(25):8601-11. doi:10.1021/jacs.7b03334

13. Fox BS, Kantak KM, Edwards MA, Black $\mathrm{KM}$, Bollinger BK, Botka AJ, et al. Efficacy of a therapeutic cocaine vaccine in rodent models. Nat Med 1996 2:10. Nature Publishing Group; 1996 Oct 1;2(10):1129. doi:10.1038/nm1096-1129

14. McCluskie MJ, Thorn J, Mehelic PR, Kolhe P, Bhattacharya K, Finneman JI, et al. Molecular attributes of conjugate antigen influence function of antibodies induced by anti-nicotine vaccine in mice and non-human primates. Int J Immunopharmacol. 2015 Apr;25(2):518-27. doi:10.1016/j.intimp.2015.02.030

15. Rüedi-Bettschen D, Wood SL, Gunnell MG, West CM, Pidaparthi RR, Carroll FI, et al. Vaccination protects rats from methamphetamine-induced impairment of behavioral responding for food. Vaccine. 2013 Sep;31(41):4596-602. doi:10.1016/j.vaccine.2013.07.038

16. Janda KD, Treweek JB. Vaccines targeting drugs of abuse: is the glass half-empty or halffull? Nat Rev Immunol 2011 12:1. Nature Publishing Group; 2012 Jan 1;12(1):67-72. doi:10.1038/nri3130

17. Kosten TR, Domingo CB. Can you vaccinate against substance abuse? Expert Opin Biol Ther. 4 ed. Taylor \& Francis; 2013 Jul 9;13(8):1093-7. doi:10.1517/14712598.2013.791278

18. Kantak KM. Vaccines Against Drugs of Abuse. Drugs. Springer International Publishing; 2003;63(4):341-52. doi:10.2165/00003495-200363040-00001

19. Shen XY, Orson FM, Kosten TR. Vaccines Against Drug Abuse. Clin Pharmacol Ther. John Wiley \& Sons, Ltd; 2012 Jan 1;91(1):6070. doi:10.1038/clpt.2011.281

20. Nguyen JD, Bremer PT, Ducime A, Creehan KM, Kisby BR, Taffe MA, et al. Active vaccination attenuates the psychostimulant effects of $\alpha$-PVP and MDPV in rats. Neuropharmacology. 2017 Apr;116:1-8. doi:10.1016/j.neuropharm.2016.12.005

21. McClenahan SJ, Kormos CM, Gunnell MG, Hambuchen MD, Lamb P, Carroll FI, et al. Design, synthesis and biological evaluation of a bi-specific vaccine against $\alpha$ pyrrolidinovalerophenone ( $\alpha$-PVP) and 3,4methylenedioxypyrovalerone (MDPV) in rats. 
Vaccine. 2020 Jan 10;38(2):336-344. doi:10.1016/j.vaccine.2019.10.008

22. Stevens MW, Gunnell MG, Tawney R, Owens SM. Optimization of a methamphetamine conjugate vaccine for antibody production in mice. Int J Immunopharmacol. 2016 Jun;35:137-41. doi.org/10.1016/j.intimp.2016.03.028

23. Lam FC, Hung CT, Perrier DG. Estimation of Variance for Harmonic Mean Half-Lives. J Pharm Sci. 1985 Feb;74(2):229-31. doi:10.1002/jps.2600740229

24. Karila L, Lafaye G, Scocard A, Cottencin O, Benyamina A. MDPV and $\alpha$-PVP use in humans: The twisted sisters. Neuropharmacol. 2018 May 15;134(Pt A):65-72. doi:10.1016/j.neuropharm.2017.10.007

25. Knoy JL, Peterson BL, Couper FJ. Suspected impaired driving case involving $\alpha$ pyrrolidinovalerophenone, methylone and ethylone. J Anal Toxicol. 2014 Oct;38(8):615-7. doi:10.1007/s11419-0170385-6

26. Wright TH, Harris C. Twenty-One Cases Involving Alpha-Pyrrolidinovalerophenone ( $\alpha$-PVP). J Anal Toxicol. 2016 Jun;40(5):396402. doi:10.1093/jat/bkw029

27. Banaś BP, Janus $\mathrm{T}$, Majdanik S, Banaś $\mathrm{T}$, Dembińska T, Borowiak K. Fatal Intoxication with $\alpha$-PVP, a Synthetic Cathinone Derivative. J Forensic Sci . John Wiley \& Sons, Ltd (10.1111); 2017 Mar 1;62(2):553-6. doi:10.1093/jat/bkw029

28. Sykutera M, Cychowska M, BlochBoguslawska E. A Fatal Case of Pentedrone and $\alpha$-Pyrrolidinovalerophenone Poisoning. J Anal Toxicol. Narnia; 2015 May 1;39(4):3249. doi:10.1093/jat/bkv011

29. Nagai H, Saka K, International MN, 2014. Sudden death after sustained restraint following self-administration of the designer drug $\alpha$-pyrrolidinovalerophenone. Int $J$ Cardiol 172, 263-265. doi:10.1016/j.ijcard.2013.12.262

30. Anizan S, Concheiro M, Lehner KR, Bukhari MO, Suzuki M, Rice KC, et al. Linear pharmacokinetics $\quad 3,4-$ methylenedioxypyrovalerone (MDPV) and its metabolites in the rat: relationship to pharmacodynamic effects. Addict Biol. 2016 Mar 1;21(2):339-47. doi:10.1111/adb.12201

31. Horsley RR, Lhotkova E, Hajkova K, Feriancikova B, Himl M, Kuchar M, et al. Behavioural, Pharmacokinetic, Metabolic, and Hyperthermic Profile of 3,4Methylenedioxypyrovalerone (MDPV) in the Wistar Rat. Front Psychiatry. Frontiers; 2018 Apr 24;9. doi:10.3389/fpsyt.2018.00144

32. Valentine JL, Arnold LW, Owens SM. Antiphencyclidine monoclonal Fab fragments markedly alter phencyclidine pharmacokinetics in rats. J Pharmacol Exp Ther. American Society for Pharmacology and Experimental Therapeutics; 1994 Jun 1;269(3):1079-85. doi:10.1002/(ISSN)20521707

33. Owens SM, Mayersohn M. Phencyclidinespecific Fab fragments alter phencyclidine disposition in dogs. Drug Metab Dispos. American Society for Pharmacology and Experimental Therapeutics; 1986 Jan 1;14(1):52-8. doi:10.1002/(ISSN)2052-1707

34. Stevens MW, Tawney RL, West CM, Kight AD, Henry RL, Owens SM, et al. Preclinical characterization of an anti-methamphetamine monoclonal antibody for human use. MAbs. 2014 doi:10.4161/mabs.27620

35. Novellas J, López-Arnau R, Carbó ML, Pubill $\mathrm{D}$, Camarasa J, Escubedo E. Concentrations of MDPV in rat striatum correlate with the psychostimulant effect. J Psychopharmacol (Oxford). SAGE PublicationsSage UK: London, England; 2015 Nov;29(11):1209-18. Oxford). 29, 1209-1218. doi:10.1177/0269881115598415

36. Hambuchen MD, Hendrickson HP, Gunnell MG, McClenahan SJ, Ewing LE, Gibson DM, et al. The pharmacokinetics of racemic MDPV and its $(\mathrm{R})$ and $(\mathrm{S})$ enantiomers in female and male rats. Drug Alcohol Depend. Elsevier; 2017 Oct 1;179:347-54. doi:10.1016/j.drugalcdep.2017.07.011. 